\title{
A Monetarist Model for Economic Stabilization: Review and Update
}

\author{
Keith M. Carlson
}

觡 N APRIL 1970, Leonall Andersen and I published an article, "A Monetarist Model for Economic Stabilization," in this Review.' In this article, we developed a small model of the U.S. economy purpotting to explain the movements of certain key economic aggregales, namely, nominal GNP, outpul (real GNP), prices, zun* employment and short- and long-term interest rates. The model's focus was on the role of monetary aggrem gates, in particular, M1, in the detemination of these econornic variables.

The purpose of the present article is to review this model in light of developments since 1970. This review begins with a discussion of the development of the original model and is followed by an explanation of the key differences between it and the current version of the model. This current version is analyzed by demonstrating its response to shocks and its ability to simulate, ex post, movements of nominal GNP, output, prices, unemployment and interest rates.

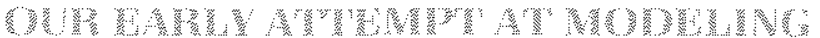

In 1970, macroeconomic model-building was a popular exercise. The Michigan and Whamon models, which had existed for a number of years, were continually being modified and updated. The FRBMIT' model, first published in 1968, was still being refined.: The Data Resources model was in the development

\footnotetext{
Andersen and Carison (1970).

2See Klein and Bumeister (1976), pp. 188-210 and pp. 248-70.

${ }^{3}$ de Leeuw and Gramlich (1968 and 1969).
}

stage. Each of these models contained a large numbet of equations and focused on a sectoral breakdown of GNP derived from the Keynesian approach to GNP determination.

Andy and I felt that these models did not place proper emphasis on the role of monetary actions. Furthermore, they focused primarily on the short sun - a projection horizon of, at most, several quarters. We wanted a model that moved from the short-run to a long-pun dynamic equilibrium with appropriate recognition being given to initial conditions in this process. In addition, we wanted a model that was small enough that the inferrelationships among the variables could be understood easily. Moreover, we sought to build on existing research at this Bank, combining various results to shed light on the issue of economic stabilization in a way that would overcome some of the shortcomings of large-scale Keynesianm style models.

Our concerns about the state of model-building strongly influenced our efforts to develop an alternative macroeconomic model of the U.S. economy. We were not concerned about respecifying behavioral equations ffor example, consumption, investment, etc.; rather, we wanted to capture empirical relationships between a relatively few key macroeconomic variables that were implicitly grounded in economic theory.

The fundamental building block of our model was the Andersen-Jordan (A-J) equation, which focused on

"Klein and Burmeister (1976), pp. 211-31. 
the two chief arms of policymaking, monetary and fiscal actions." Although this equation did not provide a model of GNP determination, it was useful in fore casting and in policy simulations. In the A-J equation, GNE was "determined" solely by current and past monetary and fiscal policy actions; other influences on GNP were found to be random during the sample period investigated by Andersen-Jordan.

Another important building block in the construction of the Andersen-Carlson (A-C) model was the interest rate equation, developed by Yohe and Karnosky in 1969 , in which interest rates were systematically related to past inflation." Then results were consistent with the Fisherian theory of interest in that they showed that inflation premia are incorporated into nominal interest rates.

To complete the model, we needed equations for the unemployment rate and the price levet. The most famous and generally accepted unemployment rate equation, developed by Arthtir Okun, was easily modifed for our purposes. This equation combines a given potential GNP with actual GNP to provide an estimate of the unemployment rate.

Finding an appropriate price equation was a more challenging task. Most large models used a wagemarkup equation and, in some cases, some type of Phillips curve equation. These equations did not fulfill our requirements. Instead, we developed a price equa tion that combined the Phillips curve results with price expectations." We used the coefficients on the inflation terms in the long-term interest vate equation as our measure of price expectations. We thought our approach was novel, and it seemed to work quite satisfactorily at the time. In retrospect, it seems rudimentary and has not worked as well in recent years.

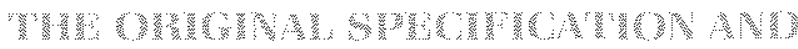

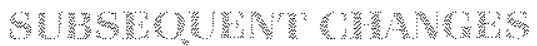

The original model was recursive, with the particular form of each equation detemined, for the most part, by the data. Since 1970 , sevenal changes have been made in the model in tems of the form of the equations and the exogenous variables that are included.

The original and current versions of the $A-C$ model are summarized in table 1 . The model still has the same number of key endogenous variables; however, the three GNP variables - total spending, output and prices - are now specified in rates of change instead of first differences. This change was made in the 1970s, when the first-difference form began to exhibit heteroskedasticity. In any event, the rate-of-change form is easier to interpret, and the fundamental properties of the model are unchanged. Monetary actions have a short-run effect on output and a long-run effect on prices; fiscal actions have little effect on output or prices in either the shoft- of long-run.

Another change was the addition of two more exogenous variables - energy prices and exports. This change, necessitated by developments in the $1970 \mathrm{~s}$, was a crude way to incorporate such complex factors. "Nevertheless, it enabled us to keep the model small. Furthermore, changes in energy prices also enter the current model through their influence on potential GNP.

Another change, not shown explicitly in table 1 , is the redefinition of two exogenous variables - potential GNP and fedetal expenditures. Potential GNP is now estimated using production-function methods developed by Rasche and Tatom." Federal expendi" tures are now cyclically adjusted rather than highemployment. ${ }^{3}$ The rationale underlying the fiscal measure remains the same - to construct a measure of federal spending that excludes the cyclical effect of the economy on the budget.

Finally, in the current version, the price, long-term interest rate and unemployment equations are adjusted for autocorrelation to avoid biasing the estimated standard errors of the coefficients.

Although these changes make it impossible to compare meaningfully the summary statistics for the two versions, the two versions show similar estimates of the impact of monetary and fiscal actions. An equation-by-equation comparison is summarized in the shaded insert on page 21 .

\footnotetext{
sAnderseri and Jordan (1968).

'Yohe and Karnosky (1969).

7 Okun (1962)

asee Considine (1969).
}

\footnotetext{
${ }^{9}$ Carison (1978).

torasche and Tatom (1977b).

"Rasche and Tatom (1977a).

${ }^{12}$ de Leeuw and Holloway (1983).
} 
Table 1

\section{St. Louis Model: Original vs. Current Version}

Original version

Sample period: /1953-IV/1969

(1) Total spending equation

$$
\begin{aligned}
& \Delta Y_{i}=2.67+\sum_{i=0}^{4} m_{i} \Delta M_{t-i}+\sum_{i=0}^{4} e_{i} \Delta E_{1-i} \\
& \Sigma m_{1}=5.57 \quad \sum e_{1}=.05 \\
& A^{2}=66 \quad S E=3.84 \quad \text { DW }=1.75
\end{aligned}
$$

(2) Price equation

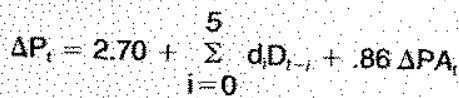

$$
\begin{aligned}
& \mathrm{zd}=09 \\
& \bar{R}=87 \quad S E=1.07 \quad D W=141
\end{aligned}
$$

(3) Demand pressure identity

$$
\mathrm{D}_{\mathrm{t}}=\Delta \mathrm{Y},\left(\mathrm{XF}-\mathrm{X}_{-\mathrm{i}}\right)
$$

(4) Total spending identity

$$
\Delta Y_{t}=\Delta P_{i}+\Delta X_{t}
$$

(5) Long-term interest rate equation

$$
\begin{aligned}
& R \mathrm{~L}_{1}=1.28-.06 \overline{\mathrm{M}}_{\mathrm{f}}+1.42 \mathrm{Z}_{\mathrm{f}} \\
& +\sum_{i=0}^{16} x_{i} \dot{X}_{i-i}+\sum_{i=0}^{16} p_{i}\left(\frac{\dot{P}_{i-i}}{U_{i-i} / 4}\right) \\
& \Sigma X_{i}=.20 \quad \Sigma p_{i}=.96 \\
& \bar{R}^{2}=.92 \quad S E=.28 \quad \text { DW }=.69
\end{aligned}
$$

(6) Anticipated price definition

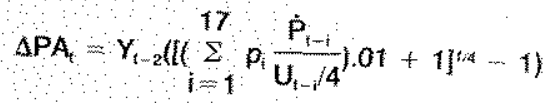

$$
\begin{aligned}
& \Sigma p_{i}=96
\end{aligned}
$$

(7) Unemployment rate equation

$$
\begin{aligned}
& \mathrm{U}_{\mathrm{H}}=3.90+04 \mathrm{G}_{\mathrm{t}}+28 \mathrm{G}_{t-\xi} \\
& \mathrm{A}^{2}=92 \quad \mathrm{SE}=30 \quad \mathrm{DW}=60
\end{aligned}
$$

(8) GNP gap identity

$$
\dot{G}_{t}=\frac{X F_{t}-X_{t}}{X F_{t}} .100
$$

\section{Current version}

Sample perioc: I/1960-IV/1984

(1) Total spending equation

$$
\begin{aligned}
& \grave{Y}_{1}=3.08-4.28 Z 1_{t}+\sum_{j=0}^{3} m_{j} \dot{M}_{1-i} \\
& +\sum_{i=0}^{4} e_{i} E_{i, i}+\sum_{i=0}^{3} e x_{i} \dot{E} X_{t-i} \\
& \Sigma m_{i}=96 \quad \Sigma e_{i}=.07 \quad \quad \Sigma e x_{i}=.00 \\
& \mathrm{~A}^{2}=32 \quad S E=3.91 \\
& \text { DW }=2.22
\end{aligned}
$$

(2) Price equation

$$
\begin{aligned}
& P_{1}=96+\sum_{l=0}^{3} p e p E_{1-3} \\
& \sum_{0}^{5} \mathrm{dD}_{\mathrm{D}}+\mathrm{APPA}_{\mathrm{P}} \\
& -9622+.8023_{1} \\
& \Sigma p e=09 \quad \Sigma d=08 \quad 0=01 \\
& \mathrm{~A}^{2}=77 \quad \mathrm{SE}-148 \quad \mathrm{DW}=1.98
\end{aligned}
$$

(3) Demand pressure identity

$$
D_{t}=X_{t}-\left(\left(X F_{1} / X_{-1}\right)^{4}-11100\right)
$$

(4) Total spending identity

$$
\dot{Y}_{f}=\dot{P}_{t}+\dot{X}_{i}
$$

(5) Longterm interest rate equation

$$
\begin{gathered}
\mathrm{RL}_{\mathrm{l}}=5.66+\sum_{\mathrm{j}=0}^{20} \mathrm{p} \dot{P}_{\mathrm{i}-\mathrm{i}} \\
\vdots \mathrm{p}_{\mathrm{i}}=.55 \quad \hat{\rho}_{1}=1.15 \quad \hat{\rho}_{2}=-.16 \\
\bar{R}^{t}=.07 \quad \mathrm{SE}=.42 \quad \mathrm{DW}=1.96
\end{gathered}
$$

(6) Anticipated price defintion

$$
\begin{aligned}
& P_{A_{1}}=\frac{21}{5} p_{p-i} \\
& \Sigma p_{i}=.55
\end{aligned}
$$

(7) Unemployment rate equation

$$
\begin{aligned}
& U_{1}-U F_{E}=29 G_{1}+16 G_{9 \neq} \\
& \tilde{\rho}_{1}=1.20 \quad \tilde{p}_{x}=0.33 \\
& \overline{\mathrm{R}}^{2}=.71 \quad \mathrm{SE}=21 \quad \mathrm{OW}=1.95
\end{aligned}
$$

(8) GNP gap identity

$$
G_{t}=\frac{X F_{t}-X_{i}}{X F_{1}} \cdot 100
$$




\section{The St. Louis Model: Original vs. Current Versions}

The total spending equation has been changed from a first-difference to a rate of-change form, and the rate of change of exports and a dummy variable, designed to capture in a crude way the velocity shift after 1981 , have been added. The lag on money was also shortened by one quarter.

In the current version, the price equation has three additional variables and is now in rate-ofchange form. Energy prices are now included as an independent variable, and dummy variables representing priee control and decontrol in the early 1970 s are also included The demand pressure variable (equation 3 ) has been redefined to avoid mixing nominal and real variables. Demand pressure is defined now as actual output growth relative to its potential to expand The coefficient on anticipated prices, 168 , now appears out of line with both theoretical and past empirical estimates However. when the sum for $\dot{P}$ in the long term interest equation, 55 , is taken into account, the product of the two coefficients, $(1.68 \times 55)$, is more in line with theoretical expectation.

Unlike the rest of the equations, the long-term interest rate equation is essentially unchanged. Since its sole function is to generate the weights on past prices to use in the measure of anticipated prices, the results for the early version had considerable appeal because $\Sigma_{p}$ was close to one this result is not observed in the current version $\mathrm{Al}$ though the form of the equation is now much simpler, the fit of the equation, which includes an autocorrelation adjustment, is very poor The good fit of the original result was misleading because the residuals were highly correlated.

The seemingly major change in the form of equa tion 6 , which defines anticipated inflation, results from the change from first-difference to rate-ofchange form. The current version is much easier to interpret being simply a weighted sum of past rates of price changes

Finally, the unemployment equation has changed only slightly Essentially, the constant in the original version has been replaced by the fullemployment unemployment rate. This rate is intended to be consistent with the estimate of potential GNP.

Table 1 Continued...

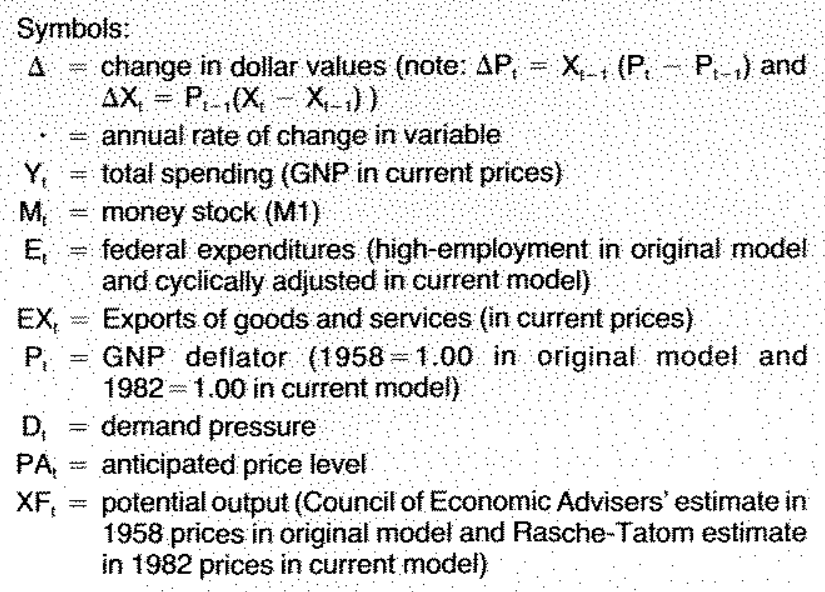

$X$ output (GNP in 1958 prices in original model and GNP in 1982 prices in current model)

$P E_{1}=$ elative price of energy

$\mathrm{RL}_{1}$ - conporate Aaa bond rate

$U_{1}$ = cullan unemployment rate

$\mathrm{G}=$ GNP gap as a percent of potential output

$z_{1}=$ dummy variable $(/ / 1955-1$ V/ $1960=0,1 / 1961-1$ / $1969=1)$

$Z 1_{1}=$ dummy variable $(1 / 1960 / \mathrm{V} / 1981=0, / / 1982-\mathrm{V} / 1984=1)$

$Z_{2}=$ price control dummy $(1 / 1960-1 / 1971,1 / 1973 \mathrm{IV} / 1984=0$ $11 / 1971-1 / 1973=1)$

$Z 3_{1}=$ post-price control dummy $(\mathrm{V} / 1960-1 / 1973,1 / 1975-\mathrm{IV} / 1984$ $=0,(1 / 1973-1 / 1975=1)$ 


\section{Table 2}

\section{The Current Model's Response to a Fiscal Shock (shocked values denoted by prime)}

\begin{tabular}{|c|c|c|c|c|c|c|}
\hline \multirow{2}{*}{$\begin{array}{l}\text { Quarters } \\
\text { elapsed }\end{array}$} & \multirow{2}{*}{ Exogenous variable } & \multicolumn{5}{|c|}{ Endogenous variables } \\
\hline & & $\mathbf{Y r}$ & $x / x$ & $\mathbf{P} / \mathbf{P}$ & $\mathrm{Uu}$ & $\mathbf{R L}-\mathbf{R L}$ \\
\hline 1 & 10454 & 10025 & 10022 & 10001 & 0661 & 001 \\
\hline 2 & 10440 & 10035 & 10027 & 10002 & 107 & 004 \\
\hline 3 & 10444 & 1,0032 & 10035 & 10005 & +137 & 009 \\
\hline 4 & 10445 & 10030 & 10017 & 10008 & 009 & 015 \\
\hline 5 & 10457 & 100036 & 10028 & 10011 & 105 & 020 \\
\hline 6 & 10461 & 10036 & 1.0029 & 10014 & 125 & 026 \\
\hline 7 & 1,0454 & 100036 & 1,0025 & 10018 & -116 & 033 \\
\hline 8 & 10455 & 10035 & 10020 & 10022 & 1095 & 038 \\
\hline 12 & 10458 & 10036 & 1,0000 & 10033 & -004 & 053 \\
\hline 16 & 10479 & 10037 & 9998 & 10041 & 020 & 056 \\
\hline 20 & 10467 & 100036 & 9983 & 110047 & 067 & 053 \\
\hline 24 & 1.0436 & 100034 & 9988 & 10050 & 049 & 040 \\
\hline 28 & 10424 & 10033 & 997 & 1,0051 & 082 & 025 \\
\hline 32 & 10391 & 10031 & 9984 & 10046 & 067 & 003 \\
\hline 36 & 10422 & 10032 & 9990 & 100039 & 046 & $\lcm{015}$ \\
\hline 40 & 10412 & 10032 & 10002 & 10033 & 0008 & 026 \\
\hline
\end{tabular}

NOTE To calculate percent change for $E, X$ and $P$ subtracl 1 and multiply by $100, U-U$ and $R L$ - are differences of percents

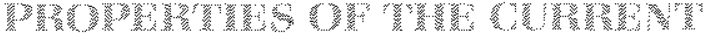

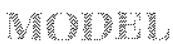

To demonstrate the properties of the current model, it was subjected to three different "shocks." In each case, the shock began in $\mathbf{1} / 1975$, and the simblated response was calculated through IV/1984. The three shocks are: :13

1. Fiscal shock. An increase in cyclically adjusted expenditures equal to 1 percent of GNP.

2. Monetary shock. A gradual increase in M1 over a year to 3 percent above the base path.

3. Supply-side shock. A lowering of the wortd oil price by 20 percent.

The results of simulating the model with each shock are shown in tables $2-4$. These results are summarized in table 5 .

\footnotetext{
"These are the shocks simulated for Professor Klein's model comparison seminar, which was reorganized in 1985. For results of the earlier seminar in the 1970s, see Klein and Burmeister (1976).
}

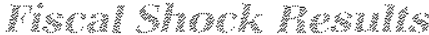

The increase in cyclically adjusted expenditures quickly influences total spending. The total effect, however, is at most a .37 percent increase of a measured elasticity of 08 . The fiscal multiplier, $\Delta \mathrm{Y} / \Delta \mathrm{E}$, using average values for 1978-79 the middle of the sample period), is 38 . This is much lower than other econometric models. ${ }^{54}$

The dynamics of the model indicate that the initial increase in total spending is transmitted first and temporarily to real GNP, then fully to the price level. In fact, it appears that the price level overshoots its final equilibrium, implying an undershooting of real GNP. Output and the price level continue to oscillate after 40 quarters, but the fiscal shock has essentially no effect on output in the long run. Consequently, the effect on the unemployment rate is small, with the oscillation of the unemployment pate synchronous with output. Similarly, the effect on the Iong-term interest rate is negligible even four or five years after the shock, as interest rates rise with inflation and fall when the rate of inflation declines.

\footnotetext{
${ }^{4}$ See Klein and Burmeister (1976), p. 338
} 


\section{Table 3}

The Current Model's Response to a Monetary Shock (shocked values denoted by prime)

\begin{tabular}{|c|c|c|c|c|c|c|}
\hline \multirow{2}{*}{$\begin{array}{l}\text { Ouarters } \\
\text { elapsed }\end{array}$} & \multirow{2}{*}{ Exogenous variable } & \multicolumn{5}{|c|}{ Endogenous variables } \\
\hline & & $\mathbf{Y}$ & $\mathbf{x} \mathbf{X}$ & $P / P$ & $\mathbf{u}-\mathbf{u}$ & $A L-R L$ \\
\hline 1 & 10014 & 1,0004 & 10003 & 10000 & -007 & 000 \\
\hline 2 & 10073 & 10026 & 10019 & 10001 & 057 & 002 \\
\hline 3 & 10188 & 10081 & 10084 & 10004 & -262 & 008 \\
\hline 4 & 10280 & 10163 & 10145 & 10012 & -532 & 024 \\
\hline 5 & 10300 & 10231 & 10208 & 10026 & -810 & 051 \\
\hline 6 & 10300 & 10265 & 10226 & 10045 & 961 & 086 \\
\hline 7 & 10300 & 100272 & 1,0212 & 100067 & -946 & 125 \\
\hline 8 & 10300 & 100272 & 10186 & 110090 & -851 & 167 \\
\hline 12 & 10300 & 10272 & 10087 & 10181 & -421 & 308 \\
\hline 16 & 1.0300 & 10272 & 1.0016 & 10258 & 0087 & 390 \\
\hline 20 & 10300 & 10272 & 9948 & 10019 & 202 & 414 \\
\hline 24 & 10300 & 1,0272 & 9919 & 10361 & 339 & 371 \\
\hline 28 & 10300 & 10272 & 9891 & 10380 & 450 & 272 \\
\hline 32 & 10300 & 10272 & 9904 & 10370 & 402 & 140 \\
\hline 36 & 10300 & 10272 & 9930 & 10341 & 311 & 014 \\
\hline 40 & 1.0300 & 10272 & 9965 & 1,0311 & 164 & 076 \\
\hline
\end{tabular}

NOTE $T$ calculate percent change for $M, Y, X$ and $P$ subtract 1 and multiply by $100, U$ - $U$ and $R L$ R are differences of percents

\section{B}

A monetary shock works though the model in the same way the fiscal shock does - via total spending. The difference is that the effect is much faster and large: Nomally, a monetary shock is fuly rellected in total spending after four quarters (see equation 1 in table 11. With the experiment reported here, M1 builds up over a year's time to 3 percent above the base path. Consequently, the full effect on total spending is not registered until the seventh quarter.

The dynamics of the model take over quite quickly with respect to outpul and the price level. Output initially rises, but after four yeas retums close to its base path lovel; it then falls below the base level as the inflation rate continues to increase. In fact the elasticity of the price level peaks at 1.27 after seven years. The 40 -quarter simulation is not long enough to determine the nature of the long-run equilibrium.

The monetary shock produces a strong oscillatory novement in the unemployment rate. Initially, this rate drops quickly, falling to almost one percentage point below its base path after only six quarters. After four years, $U$ moves back to its base path and then increases above it, staving there for the remainder of the simulation period.
The effect of the monetary shock on interest de pends directly on the price level response. Inflation and interest rates respond slowy to the shock. As long as inflation increases, interest wates rise above their base path. When inflation slows after about seven years, interest fates move back toward their base path. As with several other variables, the simulation period is not long enough to detemme the natue of the final equilbrium.

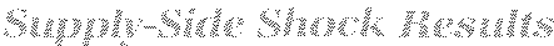

To simulate the effect of a supply shock, the price of oil per barrel was assumed to drop 20 percent, which reduces the relative price of energy by 8 percent. This variable directly affects the price equation and indirectly affects the price level because the drop in the price of oil is assumed to instantaneously increase potential outpul by 4 percent." By assumption, total spending is not affected by the supply shock, that is, the relative price of energy is not included in the total spending equation. This assumption is in dispute, however, as Tatom argues that total spending is lemporarily affected by such a shock.".

\footnotetext{
15Rasche and Tatom (June 1977).

16Tatom (1981). His argument rests on the significance of only one of the lagged values of PE. For this reason, this variation has not been introduced into the version of the model summarized in table 1
} 
Table 4

The Current Model's Response to a Supply-Side Shock (shocked values denoted by prime)

\begin{tabular}{|c|c|c|c|c|c|c|c|}
\hline \multirow{2}{*}{$\begin{array}{l}\text { Quarters } \\
\text { elapsed }\end{array}$} & \multicolumn{2}{|c|}{ Exogenous variables } & \multicolumn{5}{|c|}{ Endogenous variables } \\
\hline & PE'PE & $\mathbf{X F} / \mathbf{X F}$ & $\mathbf{Y}^{\prime} \boldsymbol{Y}$ & $\mathbf{X}^{\prime} / \mathbf{X}$ & $\mathbf{P} / \mathbf{P}$ & $\mathbf{U}-\mathbf{U}$ & RL'-RL \\
\hline 1 & 9200 & 1.0040 & 1.0000 & 1.0000 & .9998 & .109 & -.003 \\
\hline 2 & 9200 & 1.0040 & 1.0000 & .9999 & .9996 & .172 & $\therefore .009$ \\
\hline 3 & 9200 & 1.0040 & 1.0000 & 1.0015 & .9992 & 130 & -.016 \\
\hline 4 & 9200 & 1.0040 & 10000 & 1.0006 & .9988 & 132 & -.023 \\
\hline 5 & 9200 & 1.0040 & 10000 & 1.0019 & .9984 & 110 & -0.030 \\
\hline 6 & 9200 & 1,0040 & 10000 & 10026 & 9981 & .071 & -035 \\
\hline 7 & 9200 & 1.0040 & 1.0000 & 1,0030 & 9978 & .049 & -.040 \\
\hline 8 & 9200 & 1,0040 & 10000 & 1.0031 & 9975 & .040 & -044 \\
\hline 12 & 9200 & 1.0040 & 10000 & 10035 & 9963 & 030 & -058 \\
\hline 16 & 9200 & 1.0040 & 10000 & 1.0049 & 9953 & -025 & -.064 \\
\hline 20 & 9200 & 10040 & 10000 & 10048 & 9946 & .039 & -.059 \\
\hline 24 & 9200 & 10040 & 10000 & 10061 & 9944 & .093 & -.043 \\
\hline 28 & 9200 & 10040 & 10000 & 1.0050 & 9946 & -.057 & $\div .022$ \\
\hline 32 & 9200 & 10040 & 10000 & 10050 & 9948 & -.044 & -.004 \\
\hline 36 & 9200 & 10040 & 10000 & 1,0044 & 9953 & -018 & .011 \\
\hline 40 & 9200 & 10040 & 10000 & 1.0046 & 9957 & -.029 & .019 \\
\hline
\end{tabular}

NOTE, To calculate percent change for $P E, X F, Y, X$ and $P$, subtract 1 and multiply by $100 . U$ - $U$ and $R L$ afe differences of percents.

Table 5

Estimated Elasticities for the Current Model

\begin{tabular}{|c|c|c|c|c|c|c|c|c|c|}
\hline \multirow{2}{*}{$\begin{array}{l}\text { Quarters } \\
\text { elapsed }\end{array}$} & \multicolumn{3}{|c|}{$\begin{array}{l}\text { With respect to } \\
\text { fiscal shock (E) }\end{array}$} & \multicolumn{3}{|c|}{$\begin{array}{l}\text { With respect to } \\
\text { monetary shock (M) }\end{array}$} & \multicolumn{3}{|c|}{$\begin{array}{l}\text { With respect to } \\
\text { supply shock (PE) }\end{array}$} \\
\hline & $Y$ & $x$ & $\mathbf{P}$ & $Y$ & $x$ & $\mathbf{P}$ & $Y$ & $x$ & $P$ \\
\hline 1 & .06 & .05 & .00 & .29 & 21 & .00 & .00 & -.00 & .00 \\
\hline 2 & .08 & .06 & .00 & .36 & .26 & .01 & .00 & .00 & .01 \\
\hline 3 & .07 & .08 & .01 & .43 & .45 & .02 &, 00 & -.02 & 01 \\
\hline 4 & .07 & .04 & .02 & .58 & .52 & .04 & .00 & -.01 & .02 \\
\hline 8 & .08 & .04 & .05 & .91 & .62 & .30 & .00 & -.04 & .03 \\
\hline 12 & .08 & .00 & .07 & .91 & .29 & .60 & .00 & -.04 & .05 \\
\hline 16 & .08 & -.00 & .09 & .91 & .05 & .86 & .00 & -.06 & .06 \\
\hline 20 & .08 & -.04 & .10 & .91 & -.17 & 1.06 & .00 & -.06 & .07 \\
\hline 24 & .08 & -.03 & .11 & .91 & -.27 & 1,20 & .00 & -.08 & .07 \\
\hline 28 & .08 & -.05 & .12 & .91 & .36 & 1.27 & .00 & $\cdots .06$ & .07 \\
\hline 32 & .08 & -.04 & .12 & .91 & -.32 & 1.23 & .00 & -.06 & .07 \\
\hline 36 & .08 & -.02 & .09 & .91 & -.23 & 1.14 & .00 & -.06 & .06 \\
\hline 40 & .08 & .00 & .08 & .91 & --.12 & 1.04 & .00 & -.06 & .05 \\
\hline
\end{tabular}

Tables 4 and 5 show that output and prices respond quite slowy to this shock. Moreover, the maximum effect, which occurs after about six years, is relatively small. In fact, the elasticities lcalculated with respect to the relative price of energy are similat in magnitude to those for federal expenditures. 
Chare 1

\section{Nominal GNP}

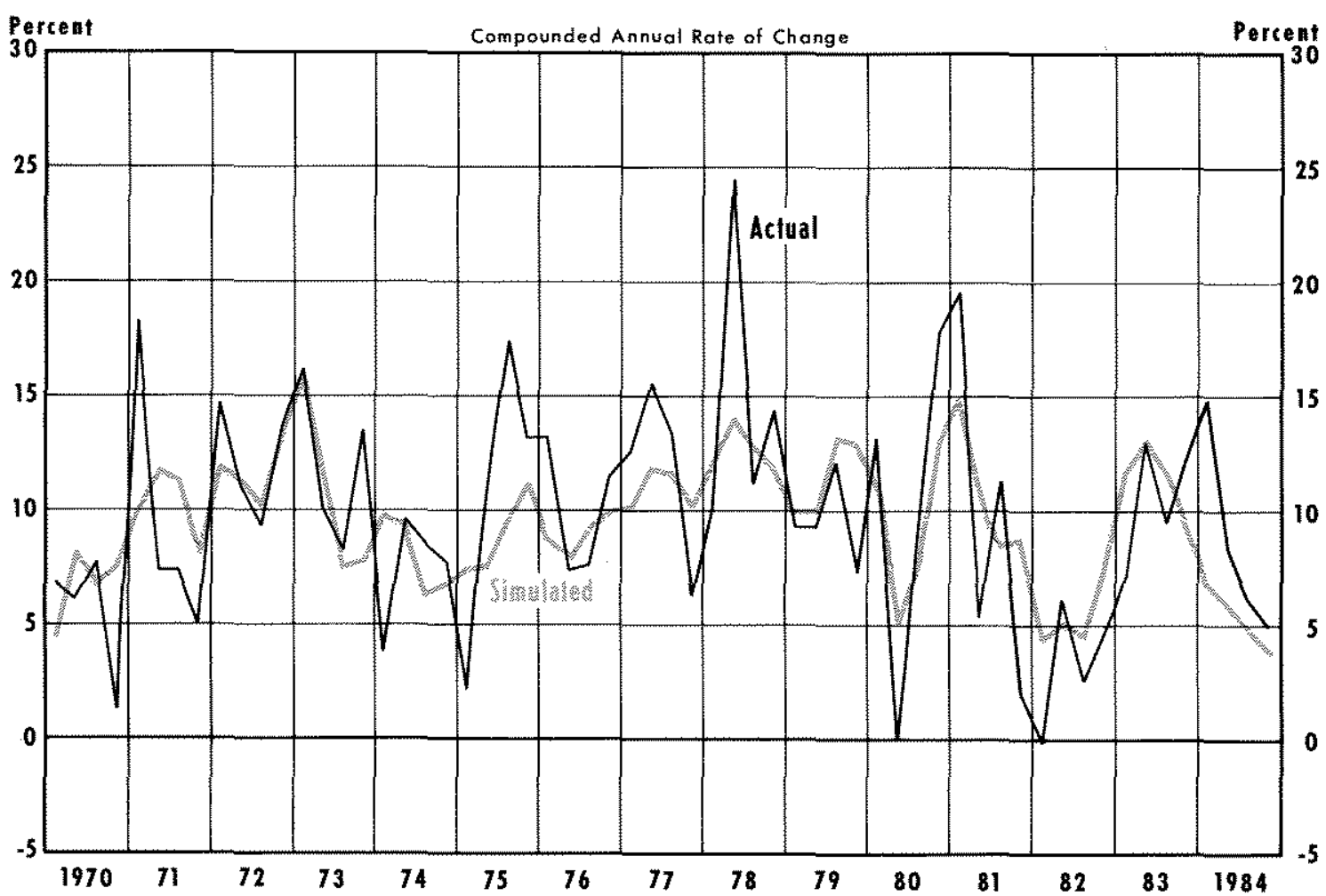

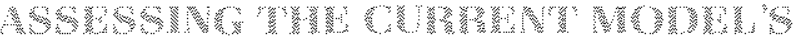

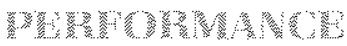

To provide some indication of model performance, the model was simulated ex post during several periods after 1969. Denoting such simulations as ex post means that all simulations were within the sample period and the exogenous variables took on their actual values. All simulations were dynamic; that is once the simulation was statted, the model generated its own lagged values.

These simulations are summarized in charts $1-3$ and table 6 . Unfortunately, these results mean little by themselves because there is no basis for comparison. Results for similar simulation exercises with other models have been published for the 1960s and early 1970s, but are not readily available for more recent periods. Consequently, any conclusions about the model's performance are impressionistic.

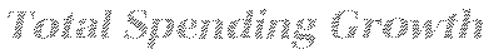

Charts $1-3$ show the results of simulating $\dot{Y}, \dot{X}$ and $\dot{P}$ for the full simulation period from 1970 through 1984. Since the total spending equation contains no endogenous variables, the model simulation shown in chart 1 simply shows the fit of that equation. That fit obviously does quite poorly on a quarter-to-quarter basis but seems to follow the contours over several quarters, almost as if a moving average had been applied to the actual observations. A desirable feature of this equation is that the quarter-to-quarter errors do not tend to cumblate over time. The errors in the estimated equafion are not correlated.

Table 6 shows that the RMSE of $Y$ increases over 
Char 2

\section{Real GNP}

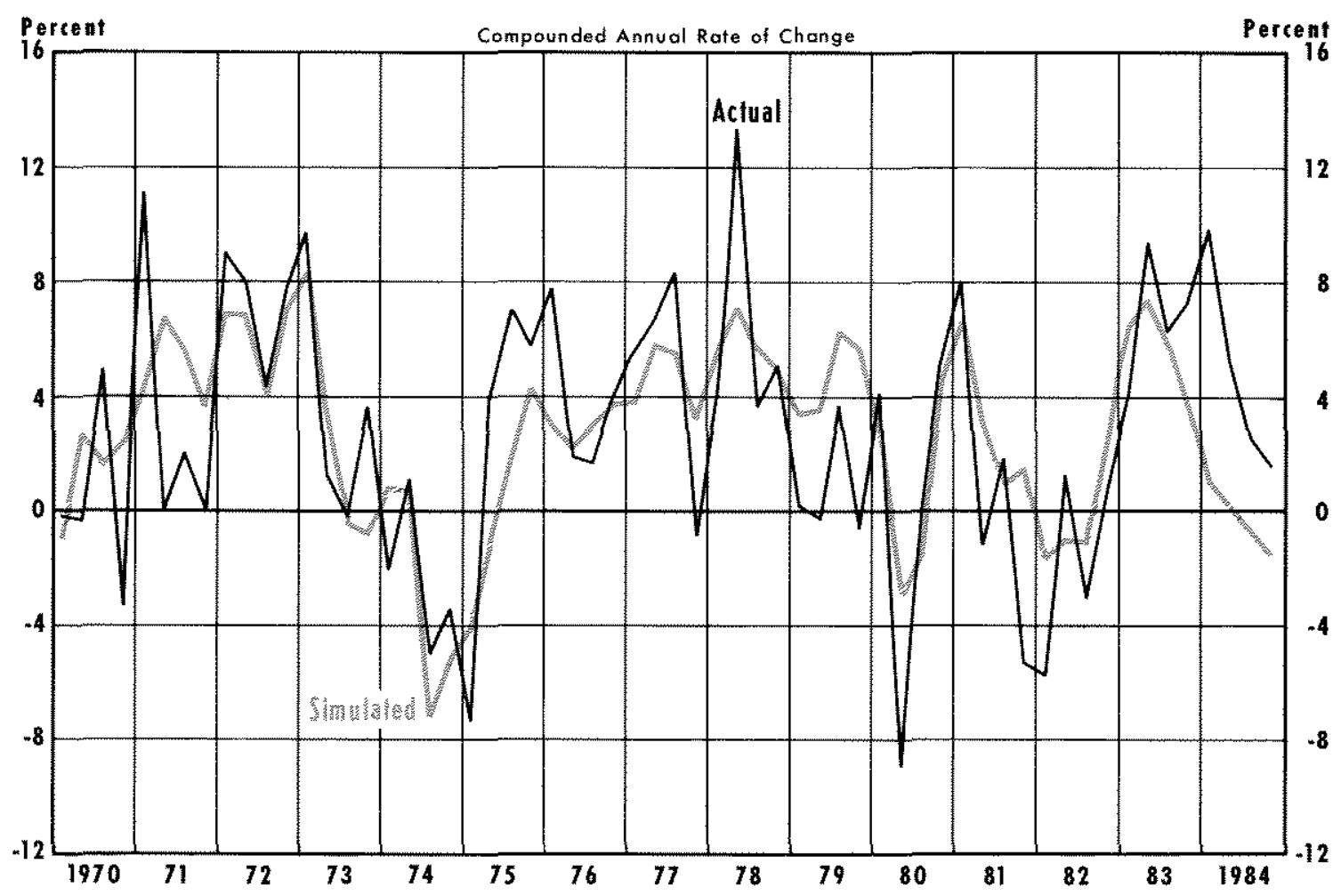

time and, even when standardized by the level of GNP (SRMSE), it continues to grow as the simulation period moves toward the present. This suggests that the relationship between $\dot{V}$ and $\dot{M}$ has become looser fecently.

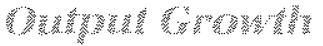

The relative degree of success in simulating total spending is carried over to the simulation of output. The model simulated $\dot{X}$ well over the periods, although if underestimated economic strength during the expansion from the $1973-75$ recession. The other period of substantial difference has occured since the thind quarter of 1983 . The model indicated a recession, which did not occur.

When the model is simulated over different periods, no consistent pattem emerges for the SHMSE for $X$. In the 1970-84 period, the SRMSE for $X$ exceeded that for $Y$. In the 1975-84 and 1979-84 periods, however, the
SRMSE for $X$ was less than for $Y$, apparently reflecting the emerging importance of aggregate demand shocks relative to supply-side shocks during these periods.

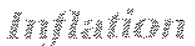

The results of simulating the inflation rate over the 1970-84 period are shown in chart 3 . Generally speaking, the movements were approximated during the 1970-77 period, but the acceleration starting in the second quarter of 1978 was not picked up until a year or so later. The essence of the general deceleration from mid-1980 was captured, but since mid-1982, the model has overestimated inflation by about 2 percentage points.

These visual impressions are borne out in the calcu" lation of RMSE for the GNP deflator. The shortest and latest period was best with a standardized RMSE of 2.62 percent. The $1975-84$ period was the worst with an SPMSE of 4.15 percent. The simulation for the 
Chart 3

\section{GNP Deflator}

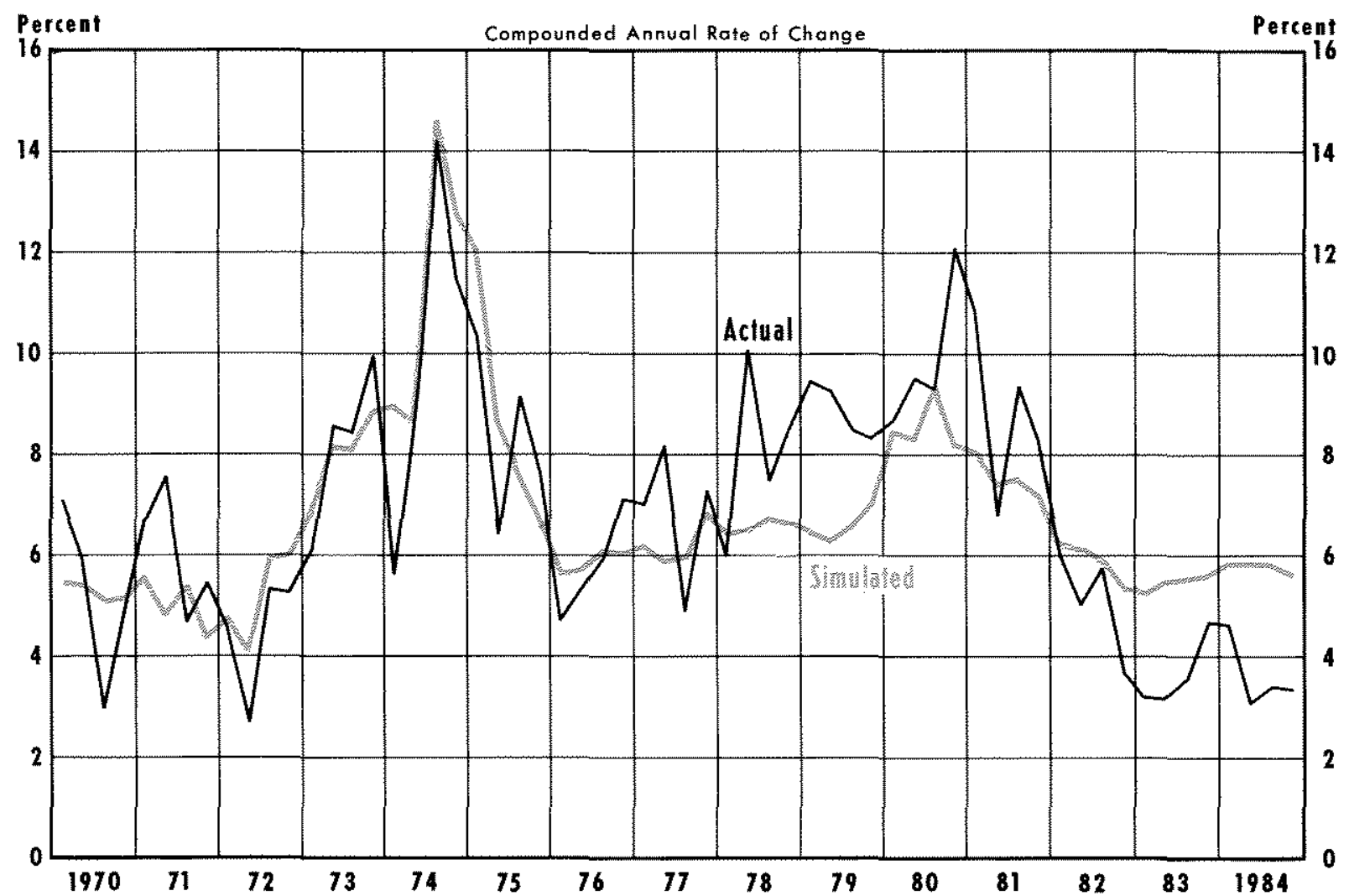

\section{Table 6}

\section{Ex Post Simulation Results}

\begin{tabular}{|c|c|c|c|c|c|c|}
\hline & \multicolumn{2}{|c|}{$170-1 / 184$} & \multicolumn{2}{|c|}{$175 \sim \mathrm{V} / 84$} & \multicolumn{2}{|c|}{$179 \mathrm{~N} / 84$} \\
\hline & RMSE & SAMSE & RMSE & SRMSE & AMSE & SRMSE \\
\hline GNP (current dollars) & 46.42 & $215 \%$ & 78.24 & $2.98 \%$ & 107.31 & $3.46 \%$ \\
\hline Real GNP (1982 dollars) & 7531 & 2.56 & 85,55 & 275 & 72.03 & 2.21 \\
\hline GNP deflator $(1982=100)$ & 199 & 2.80 & 3.45 & 415 & 2.49 & 2.62 \\
\hline Unemployment rate (percent) & 131 & 18.91 & 148 & 19.25 & 1.31 & 16.60 \\
\hline Corporate Aaa bond rate (percent) & 235 & 23.95 & 2.89 & 26.69 & 3.23 & 26.13 \\
\hline
\end{tabular}

NOTE: RMSE is root mean squared error, SRMSE is standardized RMSE, that is, RMSE divided by the level of the variable and multiplied by 100 . 
overall period was in between, with an SRMSE of 2.79 percent.

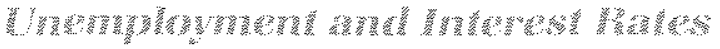

Table 6 shows that the RMSE for simulations of the civilian unemployment rate and the Aat bond rate do not vary by much over different simulation periods. The RMSE is more meaningful for these comparisons than SRMSE because the RMSE is already expressed in percentage points.

Simulations of the movements of the Aaa bond rate were generally unimpressive. Although the RMSE wats little different for the alternative simulation periods, it increased as the simulation was brought closer to the present.

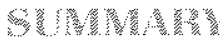

The St. Louis model, as originally published in April 1970, was designed to focus on the importance of monetary actions in the determination of spending output and prices. Its structure differed substantially from other econometric models at that time. It consisted of the Andersen-Jordan GNP equation and several other empirical relationships; it was recursive in form. It estimated GNP directly using monetary and fiscal variables, in sharp contrast to the conventional approach of estimating the components of GNP and then summing them to obtain a GNP estimate.

Since 1970 , the general form of the model has been maintained, but several changes in its specification and estimation have been made. One notable change has been simplification - using rates of change in stead of first differences. Another is the addition of supply-side variables - the relative prices of energy and price control and decontrol dummies and, most recently, a dumny in the GNP equation to capture the shift in the relationship since 1981. Other changes included atternative estimates of potential outpul and federal expenditures, and adjustments for autocomelation in several of the equations.

Despite these changes, the properties of the model remain essentially unchanged. Monetary actions have a large short-run effect on total spending, output and unemployment; over the long run, however, the effect on total spending is almost entirely reflected in the price level, with very little effect on output and unemployment. Fiscal actions have small short-run effects that disappear (in terms of output) quite quickly. While the supply-side effects are not strong according to conventional elasticities, these effects can be impor'tant if energy prices move dramatically.

The performance of the model is difficult to gatge, but, for the most part, the simulation results were decmed successful. Ex post simulations are the conventional method of assessing a model's performance, but they are more meaningful when compared with those from other models. There have been no published studies of how other models are performing in the 1980 s. A more accurate evaluation awaits comparison with similar results from other current models.

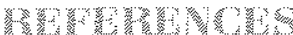

Andersen, Leonall C., and Keith M. Carlson. "A Monetarist Model for Economic Stabilization, "his Review (April 1970), pp, 7-25.

Andersen, Leonall C., and Jerry L. Jordan. "Monetary and Fiscal Actions: A Test of Their Relative Importance in Economic Stabilization," this Review (November 1968), pp. 11-24.

Carlson, Keith M. "Does the St. Louis Equation Now Believe in Fiscal Poilcy?" this Review (February 1978), pp. 13-19.

Considine, Wiltiam. "Public Policy and the Current Intlation," prepared as part of a summer intern program at the U.S. Treasury Department (September 5, 1969).

de Leeuw, Frank, and Edward Gramlich. "The Channels of Monetary Policy," Federal Reserve Bulletin (June 1969), pp. 472-91.

"The Federal Reserve-MIT Econometric Model," Federal Reserve Bulletin (January 1968), pp. $11-46$.

de Leeuw, Frank, and Thomas M. Holloway. "Cyclical Adiustment of the Federal Budget and Federal Debt," Survey of Current Business (December 1983), pp. 25-40.

Klein, Lawrence B., and Edwin Burmeister, eds. Econometric Model Performance (University of Pennsylvania Press, 1976).

Okun, Arthur M. "Potential GNP: its Measurement and Significance," 1962 Proceedings of the Business and Economic Statistics Section of the American Statistical Association, pp. 98-104.

Rasche, Robert H., and John A. Tatom. "Energy Resources and Potential GNP," this Review (June 1977a), pp. 10-24.

"The Effects of the New Energy Regime on Economic Capacity, Production, and Prices," this Review (May 1977b), pp. $2-12$

Tatom, John A. "Energy Prices and Short-Run Economic Pertormance," this Review (January 1981), pp. 3-17.

Yohe, Wiltiam P., and Denis S. Karnosky. "Interest Rates and Price Level Changes, 1952-69," this Review (December 1969), pp. 18 38. 